\title{
Correspondence
}

A Response to Competition Within the Physicians' Services Industry: Osteopaths and Allopaths

To the Editor:

It is indeed heartening to learn how much society benefits from the competition between osteopaths and allopaths according to Professor Blackstone's recent article, Competition Within the Physicians' Services Industry: Osteopaths and Allopaths, which appeared in Volume 8, Number 2 (Summer 1982). The problem, however, is that much of the data upon which his conclusions are based is erroneous or speculative and hence casts grave doubts upon the entire premise of the article.

By Professor Blackstone's own figures over ninety-six percent of all medical care rendered by physicians is attributable to allopaths. In many areas of the country, this may approach 100 percent. His point that unification would give the A.M.A. control over production of all physicians is specious. The data already shows virtual monopolistic control, by numbers, yet, less than sixty percent of allopaths are members of the A.M.A. and the recent past decade doubling and tripling of medical school enrollments including an Osteopathic School of Medicine in Ohio has been dictated by governmental policy, not A.M.A. dictates.

The Article maintains that society will greatly benefit from "increased innovation," whatever that means, and responsiveness to "unmet" consumer desires. These may be highly desirable ends, but there is no substantiation of these claims by any concrete evidence supplied by the author.

The author glibly refers to the "conspiracy of silence" canard and gives several anecdotal references of legal cases where only osteopaths were willing or available to testify in malpractice suits against allopaths in this pursuit of justice. He makes the point, citing two references as substantive authority: Markus, from Cleveland-Marshall Law Review and Harney's Medical Malpractice.

Accepting the premise that there is natural reluctance of all professionals to testify against members of their own group (even osteopaths v. osteopaths), one has only to skim the classified section of any of several weekly legal newspapers to find literally dozens of advertisements specifically devoted to testimony in malpractice cases, both allopathic and os- 
teopathic. One wonders then, in any specific case where expert medical testimony is required, how diligent the counselors have been in seeking out such requisite testimony.

The author's point of helping to overcome allopathic medicine's ability to avoid malpractice litigation on this basis is simply not substantiated by the facts, nationwide, both as to rising numbers of such cases filed and as to the numbers where only osteopathic testimony is presented against an allopathic physician. One wonders if the author has ever heard of the legal theory of res ipsa loquitur, or its use in medical malpractice tort law.

The author's point that there exists a threat of osteopathic medicine increasing its share of the market if allopathic medicine refuses to cooperate with such governmental programs as Medicaid is also groundless. The author freely admits to the paucity of osteopaths in many parts of the country and notwithstanding an altruistic drive on their part, where will all the osteopathic physicians materialize for the poor to turn to if allopaths completely negate their care?

Professor Blackstone's points of satisfying demand for a "different type" of physician are well taken. Essentially the real desire is for familytype general practice physicians. Most osteopaths fit into this category and indeed fill the "gaps" left by the preponderance of allopaths entering medical subspecialties or not wanting to practice in rural areas. Allopathic medicine is now beginning to respond to these legitimate needs.

Incredibly, the author then falls into the trap of comparing training and makes the statement that "the standard osteopathic curriculum is four years plus one year of internship, considerably shorter than the standard allopathic program." In fact, both require baccalaureate degrees prior to entrance, and some allopathic medical schools have year-round three year programs, rather than four. The internship year has virtually been abolished in allopathic medicine and now represents the first year of specialized residency training. If an allopath decides to enter practice at that stage, the training period is identical as it is if an osteopathic physician elects to undergo residency training in a specialty either in an osteopathic or allopathic program. Using this as an example of cost containment on the part of osteopathy indicates the substantive merit of the author's entire argument.

The examples of innovation in quality control cited are equally baseless. The examples presented by the author on the requirements for osteopaths to continue medical education were by legislative statute, not altruism, as were the subsequent requirements demanded for allopaths enacted following what was perceived as a "malpractice crisis" by state legislatures. Neither camp initially sought out these requirements as desirable, and allopathic medicine certainly did not follow anyone's lead in this case.

I will not debate the merits of whether there should be two schools of 
medical practice, and perhaps there are good reasons to continue in that vein. At least arguments for a cause should be factual and based on defensible : premises.

John R. Judge, M.D., J.D.

\section{The author responds:}

To the Editor:

Dr. Judge's comment reinforces the desirability of having two separate groups of physicians.

He argues that osteopathy has little influence since control over 100 percent of the physicians produced is not much different from control over 96 percent. However, even some degree of competition is better than none. If $\mathrm{Dr}$. Judge is suggesting that more osteopaths are required to increase competition, I might agree. It may be desirable if the market shares of allopathy and osteopathy were more equal, especially where there are no osteopaths. In any case, having two separate groups increases the difficulty of restricting output for the benefit of the profession. For example, there is now the real possibility that allopathic medical schools will reduce enrollment. ${ }^{1}$ Whether or not more physicians should be produced is a matter to be decided by the interaction of producers and consumers of medical care, and not by producers alone. The presence of osteopathy enhances the power of consumers. Government policy has not been the sole source of such decisions about the output of physicians.

A major point raised by Dr. Judge seems to be that osteopathy's small market share indicates the absence of competition. That observation fails to consider the important actual and potential competitive effects that can occur when a dominant firm is faced with even a small competitor. The existence of osteopaths, for example, implies that they can expand their numbers in response to a failure of allopathic medicine to satisfy consumer desires. In some industries, once-dominant firms have been supplanted by smaller firms that responded better to market demands. Moreover, the market share of osteopaths in certain areas exceeds the national average.

Dr. Judge argues that I have not shown that the existence of osteopathy has yielded innovation or responsiveness to consumer desires, though he agrees that osteopathy has filled the void in general practice and in physician-short areas. This inconsistency seems surprising. The fact that osteopathy responded first to a need for general practitioners illustrates the likelihood that, should allopathy fail to serve some other needs of consumers, the gap can be filled by osteopaths. That is indeed a primary purpose

${ }^{1}$ What's Ahead?, MED. Econ., April 13, 1981 at 238. 